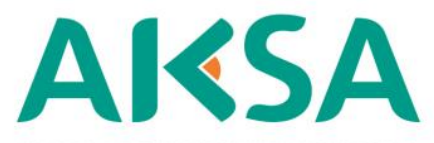

JURNAL DESAIN KOMUNIKASI VISUAL
AKSA JURNAL DESAIN KOMUNIKASI VISUAL ISSN: 2615-1111 (online) Available online at: http://aksa.stsrdvisi.ac.id

\title{
PENGUKURAN EFEKTIVITAS INFOGRAFIS PADA PORTAL BERITA ONLINE KOMPAS.COM
}

\author{
Zahrina Rahmani Humairoh $^{1}$, Dian Prajarini ${ }^{2}$ \\ ${ }^{1}$ Sekolah Tinggi Seni Rupa dan Desain Visi Indonesia \\ ${ }^{2}$ Sekolah Tinggi Seni Rupa dan Desain Visi Indonesia \\ E-mail: inaonik@gmail.com,dianpraja@gmail.com²
}

\begin{tabular}{|c|c|}
\hline ARTICLE INFO & ABSTRAK \\
\hline $\begin{array}{l}\text { Article history: } \\
\text { Received: } 11 \text { September } 2019 \\
\text { Revised: } 15 \text { September } 2019 \\
\text { Accepted: } 18 \text { September } 2019\end{array}$ & $\begin{array}{l}\text { Online media in greater demand information because the } \\
\text { community in looking for quick and easy to access, one of the } \\
\text { pioneer is Kompas.com which become a reference to journalism } \\
\text { amid all the uncredible information. Nowadays, the Public has }\end{array}$ \\
\hline $\begin{array}{l}\text { Keywords: } \\
\text { Infographic } \\
\text { Effectiveness } \\
\text { Kompas.com }\end{array}$ & $\begin{array}{l}\text { limited time to read and understand the news that contains much } \\
\text { texting, that is why kompas.com presenting news in infographics with } \\
\text { that look attractive but can convey that complex information being } \\
\text { easy and fast to understand by the Society. This study focused on the } \\
\text { right standard infographics and submission of a simple } \\
\text { understanding of infographics that rises for five months of every } \\
\text { month taken samples three randomly infographics. The purpose of } \\
\text { this research is to evaluate infographic design in the online news } \\
\text { website Kompas.com and to see whether the purpose in Kompas.com } \\
\text { infographics suitable for the purpose with four important uses } \\
\text { categories: usability, readable, design, and aesthetics. The } \\
\text { methodology used quantitative methods. The data to the } \\
\text { questionnaire online to FLP communities with four variables that } \\
\text { usability, readability, design, and aesthetics. The validity test is } \\
\text { using moment Pearson; and readability test using Alfa Cronbach. } \\
\text { Data analysis using descriptive statistics. } \\
\text { Based on data analysis and discussion in this research can be } \\
\text { concluded that infographic Kompas.com filled four variables } \\
\text { assessment that usability is } 80,2 \% \text {, Readable is } 80,3 \% \text {, the design is } \\
82,6 \% \text {, and aesthetics is } 79,4 \% \text {. This shows that the making of } \\
\text { Kompas.com infographics is in accordance with generation purposes } \\
\text { infographic, which is understandable, easy to read, good in visual, } \\
\text { and straight information. }\end{array}$ \\
\hline
\end{tabular}

\section{PENDAHULUAN}

Berita adalah informasi yang sedang ataupun yang telah terjadi, lalu di sampaikan dari sumber yang terpercaya. Media yang biasa digunakan dalam menyampaikan berita adalah televisi, radio, cetak, dan online. Saat ini media online lebih diminati masyarakat dalam mencari 
informasi karena mudah dan cepat untuk di akses, sehingga banyak media masa yang membuat portal berita online sebagai media dalam menyampaikan berita. Salah satu pionir media portal berita online adalah Kompas.com. Dalam menyampaikan informasi di portal berita online, terdapat beberapa kendala salah satunya yaitu masyarakat memiliki keterbatasan waktu untuk membaca dan memahami berita yang berisi banyak tulisan. Daya tarik masyarakat dalam mencari berita pun berkurang, karena itu di perlukan tampilan yang menarik namun dapat menyampaikan informasi yang kompleks menjadi mudah dan cepat di pahami oleh masyarakat. Berdasarkan kendala tersebut, Kompas.com menyajikan berita online dengan beberapa jenis salah satunya dengan infografis.

Pada penelitian dengan judul How Infographic should be evaluated? (Siricharoen \& Siricharoen, 2015), infografis harus dapat menyampaikan informasi yang kompleks namun dapat mudah dan cepat memahamkan pembaca dengan cara menarik. Informasi yang disampaikan harus berupa fakta nyata, dengan data aktual dari sumber terpercaya. Unsur-unsur visual dalam infografis sebagai pendukung dan tidak boleh mengurangi informasi yang di sampaikan. Mengevaluasi infografis diperlukan agar dapat membuat infografis yang baik dan memudahkan orang untuk memahami informasi utama dalam infografis tersebut. Penelitian lain dengan judul Infographic: Not Just a Beautiful Visualisation (Arum, 2017), infografis mudah di buat oleh siapa saja dengan bantuan pembuatan infografis di situs website, sehingga banyak infografis yang di rancang secara tidak tepat dan menyebabkan kesalah pahaman pembaca. Visual infografis yang bagus, tidak menjamin informasi yang di sampaikan dapat dipahami dan banyak juga infografis yang kurang menarik pembaca dikarenakan visualnya yang buruk. Lalu, infografis harus dievaluasi sebelum dipublikasikan untuk memastikan kualitas data dan visual yang tepat agar infografis dapat menjadi media penyampaian informasi yang ampuh dalam menyampaikan hal-hal kompleks menjadi lebih mudah dipahami oleh publik.

Mayoritas portal berita online memanfaatkan infografis sebagai produk yang memudahkan pembaca dalam memahami isu, namun ada beberapa point yang belum diterapkan secara konsisten seperti pencantuman sumber agar mudah dilacak oleh pembaca, serta aksesoris pada desain yang kurang direncanakan sehingga mengganggu fokus pembaca terhadap informasi atau menjadi salah paham (Arum, 2018). Infografis dapat menyederhanakan dari naskah yang panjang menjadi bahasa gambar yang efektif. Infografis menjelaskan runtutan sebuah proses atau kronologis kejadian menjadi bagian terpenting dalam pemberitaan (Taufik, 2012). Keberhasilan infografis dalam menyampaikan pesan yang tepat terutama pesan yang berhubungan dengan kronologi, dan proses, salah satunya ditentukan oleh layout karena berkaitan dengan urutan 
dalam membaca pesan tersebut (Rustan, 2008). Tipografi pada infografis merupakan hal yang penting oleh karena itu tipografi harus mudah dikenali dan dibedakan serta mudah dibaca (Rustan, 2010). Kontras warna sangat diperlukan dalam infografis untuk membedakan antara suatu objek dengan objek lainnya sehingga dapat dikenali seperti legability dalam tipografi dan agar informasi dalam infografis tersebut terlihat jelas oleh pembaca dengan jarak tertentu serupa dengan readability dalam tipografi (Rustan, 2019).

Infografis adalah data yang divisualkan kedalam bagan, grafis, jadwal, dan lainnya untuk mempermudah pembaca mendapatkan informasi yang cepat dan tepat. Tujuan infografis dibuat untuk menyederhanakan informasi yang kompleks, menampilkan informasi menjadi mudah di mengerti, dan mudah di jelaskan. Berdasarkan tujuan infografis, Kompas.com perlu dievaluasi untuk mengetahui apakah sudah sesuai dengan tujuan infografis agar dapat menjadi acuan berita seperti tujuan dibuatnya Kompas.com, karena itu dilakukan penelitian ini. Hipotesis dalam penelitian ini adalah mayoritas desain infografis di portal berita online Kompas.com sudah memenuhi standar infografis yang tepat dan penyampaian yang mudah dipahami dengan empat katagori utama yang di identifikasi adalah kegunaan, keterbacaan, desain dan estetika

\section{METODOLOGI}

Metode kuantitatif deskriptif, menjadi metode yang digunakan dalam penelitian ini. Populasi penelitian ini adalah Pengurus dan anggota aktif Forum Lingkar Pena (FLP) area Yogyakarta. FLP Yogyakarta, dikarenakan komunitas tersebut memerlukan sumber-sumber yang terpercaya untuk menciptakan karya tulis sehingga sesuai dengan tujuan Kompas.com yaitu ingin menjadi acuan bagi para pencari berita. Pengurus dan anggota aktif FLP area Yogyakarta berjumlah 50 orang. Hal ini berarti sampel penelitian ini sejumlah 50 orang, karena subjek kurang dari 100 (Arikunto, 2010).

Metode pengumpulan data dilakukan dengan angket online menggunakan google formulir. Variabel yang digunakan dalam pengumpulan data terlihat dalam Tabel 1.

\begin{tabular}{|c|l|l|}
\hline No. & \multicolumn{1}{|c|}{ Variabel } & \multicolumn{1}{|c|}{ Indikator } \\
\hline 1. & $\begin{array}{l}\text { Kegunaan } \\
\text { Infografis }\end{array}$ & $\begin{array}{l}\text { Infografis mudah dipahami, memiliki tujuan yang jelas, menggunakan } \\
\text { data yang andal, membuat pembaca belajar sesuatu }\end{array}$ \\
\hline 2. & $\begin{array}{l}\text { Keterbacaan } \\
\text { Infografis }\end{array}$ & $\begin{array}{l}\text { Infografis mudah dibaca, pilihan warna yang tidak menghalangi } \\
\text { kemampuan membaca, grafik dan diagram dilabeli dengan tepat, pilihan } \\
\text { font, ukuran dan warna yang digunakan untuk membuat teks }\end{array}$ \\
\hline 3. & Desain & Grafik mencerminkan tujuan dan sasaran audiens, grafik yang berkualitas \\
\hline
\end{tabular}




\begin{tabular}{|c|l|l|}
\hline No. & \multicolumn{1}{|c|}{ Variabel } & \multicolumn{1}{|c|}{ Indikator } \\
\hline & Infografis & $\begin{array}{l}\text { baik, tidak mengganggu penyampaian informasi dan konsisten, ruang } \\
\text { digunakan secara efektif, tepat menggunakan kontras dan warna }\end{array}$ \\
\hline 4. & $\begin{array}{l}\text { Estetika } \\
\text { Infografis }\end{array}$ & $\begin{array}{l}\text { Infografis mudah diikuti, keseluruhan desain memudahkan dalam } \\
\text { memahami informasi }\end{array}$ \\
\hline
\end{tabular}

Tabel 1. Indikator tiap variabel

(Sumber: Dokumentasi Penulis)

Pengukuran yang digunakan untuk tiap indikator variabel adalah skala Likert. Setiap pertanyaan tiap indikator menggunakan skala Likert mempunyai jawaban dari sangat positif sampai negatif:

1. Sangat Setuju (SS) : Skor 5

2. Setuju (S) : Skor 4

3. Netral (N) : Skor 3

4. Tidak Setuju (TS) : Skor 2

5. Sangat Tidak Setuju (STS) : Skor 1

Pengujian instrumen pengumpulan data dilakukan dengan uji validitas dan reabilitas. Sedang metode analisis data yang digunakan adalah analisis statistik deskriptif dengan cara mendeskripsikan atau menggambarkan data yang telah terkumpul sebagaimana adanya, dalam arti tidak mencari atau menerangkan saling hubungan, menguji hipotesis, membuat ramalan (Muhson, 2006). Metode yang digunakan dalam analisis statistik deskriptif ini adalah persentil dengan langkah-langkah menurut Riduwan (2004) sebagai berikut:

1. Menghitung nilai responden dan masing-masing aspek atau sub variabel.

2. Merekap nilai.

3. Menghitung nilai rata-rata.

4. Menghitung persentase dengan rumus:

$$
\mathrm{DP}=\mathrm{x} 100 \%
$$

Keterangan:

DP $=$ Deskriptif Persentase $(\%)$

$\mathrm{n}=$ Skor empiris (Skor yang diperoleh)

$\mathrm{N}=$ Skor maksimal item pertanyaan dikalikan dengan frekuensi jawaban

Hasil analisis data yang diperoleh dalam persentase, dapat dikonsultasikan dengan table kriteria pada Tabel 2 untuk menentukan katagori penilaian tiap variabel (Riduwan, 2004). 


\begin{tabular}{|c|c|c|}
\hline No. & Presentase & Kriteria \\
\hline 1. & $75 \%-100 \%$ & Sangat Tinggi \\
\hline 2. & $50 \%-75 \%$ & Tinggi \\
\hline 3. & $25 \%-50 \%$ & Rendah \\
\hline 4. & $1 \%-25 \%$ & Sangat Rendah \\
\hline
\end{tabular}

Tabel 2. Kriteria hasil analisis data

(Sumber: Riduwan, 2004)

Infografis yang dievaluasi adalah infografis Kompas.com terbit di bulan September 2018 sampai Januari 2019. Sampel tiga infografis disetiap bulannya secara acak.

\section{PEMBAHASAN}

\subsection{Deskripsi Data}

Uji validitas instrument rumus Product Moment dari Pearson (Arinkunto, 2006). Pernyataan dinyatakan valid atau layak apabila r-hitung (Corrected Item-Total Correlation) > rtabel sebesar 0.279, untuk DF (n-2): $50-2=48 ; 2$ sisi.

\begin{tabular}{|l|l|l|l|l|}
\hline \multicolumn{1}{|c|}{ Variabel } & \multicolumn{1}{|c|}{ Item } & \multicolumn{1}{c|}{ r-Hitung } & r-Tabel (n=50) & \multicolumn{1}{c|}{ Keterangan } \\
\hline Kegunaan & Keg1 & 0,549 & 0,279 & Valid \\
Infografis & Keg2 & 0,731 & 0,279 & Valid \\
& Keg3 & 0,809 & 0,279 & Valid \\
& Keg4 & 0,748 & 0,279 & Valid \\
\hline Keterbacaan & Ket1 & 0,704 & 0,279 & Valid \\
Infografis & Ket2 & 0,851 & 0,279 & Valid \\
& Ket3 & 0,834 & 0,279 & Valid \\
& Ket4 & 0,788 & 0,279 & Valid \\
\hline Desain Infografis & Des1 & 0,790 & 0,279 & Valid \\
& Des2 & 0,812 & 0,279 & Valid \\
& Des3 & 0,730 & 0,279 & Valid \\
& Des4 & 0,798 & 0,279 & Valid \\
\hline Estetika & Est1 & 0,835 & 0,279 & Valid \\
Infografis & Est2 & 0,800 & 0,279 & Valid \\
& Est3 & 0,853 & 0,279 & Valid \\
\hline
\end{tabular}

Tabel 3. Hasil uji validitas kuesioner variabel

(Sumber: Dokumentasi Penulis)

Uji Reabilitas adalah alat ukur yang memiliki konsistensi bila pengukuran yang dilakukan dilakukan berulang. Suatu konstruktur atau variabel dikatakan reliabel, jika memiliki nilai alpha Cronbach $\geq 0,50$ (Sugiyono, 2009). Berdasarkan Tabel 4, dapat disimpulkan bahwa 
setiap variabel dinyatakan reliabel karena memiliki nilai alpha Cronbach sama dengan atau lebih dari 0,5 , sehingga dapat dinyatakan bahwa seluruh pernyataan yang dibuat dinilai layak dan dapat digunakan dalam penelitian ini.

\begin{tabular}{|l|c|c|c|}
\hline \multicolumn{1}{|c|}{ Variable } & N of Item & Aplha Cronbach & Keterangan \\
\hline Kegunaan Infografis & 4 & 0,677 & Reliabel \\
\hline Keterbacaan Infografis & 4 & 0,793 & Reliabel \\
\hline Desain Infografis & 4 & 0,782 & Reliabel \\
\hline Estetika Infografis & 3 & 0,768 & Reliabel \\
\hline
\end{tabular}

Tabel 4. Hasil uji reabilitas kuesioner variabel

(Sumber: Dokumentasi Penulis)

Responden dalam penelitian ini adalah pengurus dan anggota aktif peserta Forum Lingkar Pena (FLP) area Yogyakarta, sampel dalam penelitian ini yaitu 50 responden. Pengelompokan responden dari jenis kelamin, usia, dan pekerjaan. Berdasarkan hasil pengumpulan data, diketahui sebagian besar responden adalah wanita sebanyak 37 responden (74\%), sedangkan laki-laki sebanyak 13 responden (26\%). Sebagian besar responden berumur di bawah umur 26 Tahun sebanyak 23 responden (46\%), sedangkan yang berumur antara 26 sampai 40 Tahun sebanyak 22 responden (44\%), yang berumur di atas 40 Tahun sebanyak 5 responden (10\%). Pekerjaan responden adalah pegawai negeri atau swasta sebanyak 17 responden (34\%), pelajar atau mahasiswa sebanyak 15 responden (30\%), wiraswasta sebanyak 14 responden (28\%), pekerjaan selain itu sebanyak 4 responden $(8 \%)$.

Hasil jawaban responden terhadap kuesioner tiap variabel terlihat pada Tabel 5.

\begin{tabular}{|l|l|l|l|}
\hline \multicolumn{1}{|c|}{ Variabel } & \multicolumn{1}{|c|}{ Item } & Jumlah Skor & Rata-rata \\
\hline \multirow{4}{*}{$\begin{array}{l}\text { Kegunaan } \\
\text { Infografis }\end{array}$} & Keg1 & 217 & 4,340 \\
\cline { 2 - 4 } & Keg2 & 202 & 4,040 \\
\cline { 2 - 4 } & Keg3 & 178 & 3,560 \\
\cline { 2 - 4 } & Keg4 & 205 & 4,100 \\
\cline { 2 - 4 } & Total & 802 & 16,040 \\
\cline { 2 - 4 } & Rata-rata & 3,010 \\
\hline \multirow{4}{*}{$\begin{array}{l}\text { Keterbacaan } \\
\text { Infografis }\end{array}$} & Ket1 & 197 & 3,940 \\
\cline { 2 - 4 } & Ket2 & 199 & \\
\hline
\end{tabular}




\begin{tabular}{|c|c|c|c|}
\hline Variabel & Item & Jumlah Skor & Rata-rata \\
\hline & Ket3 & 203 & 4,060 \\
\hline & Ket4 & 204 & 4,080 \\
\hline & Total & 803 & 16,060 \\
\hline & \multicolumn{2}{|c|}{ Rata-rata } & 4,015 \\
\hline \multirow{6}{*}{$\begin{array}{l}\text { Desain } \\
\text { Infografis }\end{array}$} & Des1 & 205 & 4,100 \\
\hline & Des2 & 201 & 4,020 \\
\hline & Des3 & 217 & 4,340 \\
\hline & Des4 & 203 & 4,060 \\
\hline & Total & 826 & 16,520 \\
\hline & \multicolumn{2}{|c|}{ Rata-rata } & 4,130 \\
\hline \multirow{5}{*}{$\begin{array}{l}\text { Estetika } \\
\text { Infografis }\end{array}$} & Est1 & 204 & 4,080 \\
\hline & Est2 & 194 & 3,880 \\
\hline & Est3 & 198 & 3,960 \\
\hline & Total & 596 & 11,920 \\
\hline & \multicolumn{2}{|c|}{ Rata-rata } & 3,973 \\
\hline
\end{tabular}

Tabel 5. Frekuensi jawaban tiap variabel (Sumber: Dokumentasi Penulis)

Analisis setiap pertanyaan dalam tiap variabel terlihat pada Tabel 6 menggunakan analisis deskriptif (Riduwan, 2004).

\begin{tabular}{|l|l|l|}
\hline \multicolumn{1}{|c|}{ Variabel } & \multicolumn{1}{|c|}{ Item } & \multicolumn{1}{|c|}{$\begin{array}{c}\text { Deskriptif } \\
\text { Presentase } \\
\text { (DP)(\%) }\end{array}$} \\
\hline \multirow{4}{*}{$\begin{array}{l}\text { Kegunaan } \\
\text { Infografis }\end{array}$} & Keg1 & $86,8 \%$ \\
\cline { 2 - 3 } & Keg2 & $80,8 \%$ \\
\cline { 2 - 3 } Keterbacaan & Keg3 & $71,2 \%$ \\
\cline { 2 - 3 } Infografis & Keg4 & $82 \%$ \\
\cline { 2 - 3 } & DP Variabel & $\mathbf{8 0 , 2 \%}$ \\
\cline { 2 - 3 } & Ket2 & $78,8 \%$ \\
\cline { 2 - 3 } & Ket3 & $79,6 \%$ \\
\cline { 2 - 3 } & Ket4 & $81,2 \%$ \\
\cline { 2 - 3 } & DP Variabel & $\mathbf{8 0 , 3 \%}$ \\
\hline
\end{tabular}




\begin{tabular}{|l|l|l|}
\hline \multicolumn{1}{|c|}{ Variabel } & \multicolumn{1}{|c|}{ Item } & \multicolumn{1}{|c|}{$\begin{array}{c}\text { Deskriptif } \\
\text { Presentase } \\
\text { (DP)(\%) }\end{array}$} \\
\hline \multirow{4}{*}{$\begin{array}{l}\text { Desain } \\
\text { Infografis }\end{array}$} & Des1 & $80 \%$ \\
\cline { 2 - 3 } & Des2 & $80,4 \%$ \\
\cline { 2 - 3 } & Des3 & $86,8 \%$ \\
\cline { 2 - 3 } Infografis & Des4 & $81,2 \%$ \\
\cline { 2 - 3 } & DP Variabel & $\mathbf{8 2 , 6 \%}$ \\
\hline \multirow{4}{*}{ Estetika } & Est1 & $81,6 \%$ \\
\cline { 2 - 3 } & Est2 & $77,6 \%$ \\
\cline { 2 - 3 } & Est3 & $\mathbf{7 9 , 2 \%}$ \\
\cline { 2 - 3 } & DP Variabel & $\mathbf{7 9 , 4 \%}$ \\
\hline
\end{tabular}

Tabel 6. Analisis data item tiap variabel

(Sumber: Dokumentasi Penulis)

\subsection{Pembahasan}

Jawaban responden yang telah di analisis dengan metode analisis statistik deskriptif, selanjutnya hasil yang telah didapat dikonsultasikan dengan table kriteria yang telah ditentukan pada Tabel 2. Hasil analisis data, diketahui bahwa variabel memiliki hasil antara $75 \%-100 \%$ atau masuk dalam kriteria Sangat Tinggi seperti terlihat pada Tabel 7.

\begin{tabular}{|l|l|l|}
\hline \multicolumn{1}{|c|}{ Variabel } & \multicolumn{1}{|c|}{$\begin{array}{c}\text { Deskriptif Presentase (DP) } \\
(\%)\end{array}$} & \multicolumn{1}{c|}{ Kriteria } \\
\hline Kegunaan Infografis & $80,2 \%$ & Sangat Tinggi \\
\hline Keterbacaan Infografis & $80,3 \%$ & Sangat Tinggi \\
\hline Desain Infografis & $82,6 \%$ & Sangat Tinggi \\
\hline Estetika Infografis & $79,4 \%$ & Sangat Tinggi \\
\hline
\end{tabular}

Tabel 7. Hasil analisis data

(Sumber: Dokumentasi Penulis)

Berdasarkan hipotesis dan hasil analisis data, dapat disimpulkan bahwa infografis Kompas.com memenuhi empat variabel penilaian yaitu Kegunaan Infografis dengan deskriptif persentase 80,2\%, Keterbacaan Infografis dengan deskriptif persentase 80,3\%, Desain Infografis dengan deskriptif persentase 82,6\%, Estetika Infografis dengan deskriptif persentase 79,4\%. Empat variabel yang terpenuhi ini, menunjukkan bahwa tujuan dibuatnya infografis 
Kompas.com telah sesuai dengan tujuan pembuatan infografis yaitu mudah dipahami dengan penilaian variable kegunaan infografis, mudah dibaca dengan penilaian variable keterbacaan infografis, visual yang baik dengan penilaian variable desain infografis, dan informasi yang lugas dengan penilaian variable estetika infografis.

\section{KESIMPULAN}

Berdasarkan data yang didapat dan analisis yang telah dilakukan dalam penelitian ini dapat disimpulkan bahwa infografis Kompas.com memenuhi empat variabel penilaian yaitu:

1. Kegunaan Infografis dengan deskriptif persentase $80,2 \%$

2. Keterbacaan Infografis dengan deskriptif persentase $80,3 \%$

3. Desain Infografis dengan deskriptif persentase $82,6 \%$

4. Estetika Infografis dengan deskriptif persentase $79,4 \%$.

5. Empat variabel yang terpenuhi ini, menunjukkan bahwa tujuan dibuatnya infografis Kompas.com telah sesuai dengan tujuan pembuatan infografis yang mudah dipahami, mudah dibaca, visual yang baik, dan informasi yang lugas.

\section{DAFTAR PUSTAKA}

$\underline{\text { Referensi dari buku: }}$

Arikunto, Suharsimi. 2006. Prosedur Penelitian Suatu Pendekatan Praktik. Jakarta: PT Rineka Cipta.

Arikunto, Suharsimi. 2010. Prosedur Penelitian Suatu Pendekatan Praktik. Jakarta: PT Rineka Cipta.

Riduwan. 2004. Metode dan Teknik Menyusun Tesis. Bandung: Alfabeta.

Rustan, Surianto. 2008. Layout Dasar \& Penerapannya. Jakarta: Gramedia Pustaka Utama.

Rustan, Surianto. 2010. Huruf Font Tipografi. Jakarta: Gramedia Pustaka Utama.

Rustan, Surianto. 2019. Warna. Jakarta: Batara Imaji Penerbit.

Sugiyono. 2009. Metode Penelitian Kuantitatif, Kualitatif dan R\&D. Bandung: Alfabeta

\section{$\underline{\text { Referensi dari artikel jurnal: }}$}

Taufik, Mohamad. 2012. Infografis Sebagai Bahasa Visual Pada Surat Kabar Tempo. Techno.Com, [S.1.], v. 11, n. 4, p. 156-163, nov. 2012. ISSN 2356-2579. Available at: <http://publikasi.dinus.ac.id/index.php/technoc/article/view/1010>. Date accessed: 28 Mey. 2019. doi:https://doi.org/10.33633/tc.v11i4.1010. 


\section{$\underline{\text { Referensi dari conference paper: }}$}

Siricharoen, Waralak \& Siricharoen, Nattanun. 2015. How Infographic should be evaluated?. In The 7th International Conference on Information Technology, pp. 558-564. Amman, Jordan 12-14 May 20015, Jordan: Amman.

\section{Referensi dari website:}

Arum, Nenden Sekar. 2017. Infographic: Not Just a Beautiful Visualisation [Online] URL: https://www.cs.bham.ac.uk/ rjh/courses/ResearchTopicsInHCI/201617/Submissions/arumnendensekar.pdf. Diakses pada 13 Maret 2019.

Arum, Nenden Sekar. 2018. Mencermati dan Menganalisis Infografik Ala Media Online di Indonesia [Online]

URL: https://www.academia.edu/36760356/Mencermati_dan_Menganalisis_Infografik_Ala_M edia_Online_di_Indonesia. Diakses pada 13 Maret 2019.

Muhson, Ali. 2006. Teknik Analisis Kuantitatif. [Online] URL: http://staffnew.uny.ac.id/upload/132232818/pendidikan/Analisis+Kuantitatif.pdf. Diakses pada 23 Mei 2019 